\title{
Morfologia comparada dos ovos e ninfas de Triatoma vandae Carcavallo, Jurberg, Rocha, Galvão, Noireau \& Lent, 2002 e Triatoma williami Galvão, Souza \& Lima, 1965 (Hemiptera, Reduviidae, Triatominae)
}

\author{
Maria Beatriz Araújo Silva, José Jurberg, Helene Santos Barbosa*, Dayse da Silva Rocha, \\ Rodolfo U Carcavallo, Cleber Galvão/ ${ }^{+}$
}

Laboratório Nacional e Internacional de Referência em Taxonomia de Triatomíneos *Laboratório de Biologia Estrutural, Departamento de Ultra-estrutura e Biologia Celular, Instituto Oswaldo Cruz-Fiocruz, Av. Brasil 4365,

21040-900 Rio de Janeiro, RJ, Brasil

Comparative morphology of eggs and nymphs of Triatoma vandae Carcavallo, Jurberg, Rocha, Galvão, Noireau \& Lent, 2002 and Triatoma williami Galvão, Souza \& Lima, 1965 - Eggs and all nymphs of these species were studied employing light microscopy (LM) and scanning electron microscopy (SEM). The major differences observed by LM in the eggs were related to the presence and the distribution of pores on the surface of their chorion. Morphological differences among three nymphal stages (1st, 3rd, and 5th) development of each species were observed. The differential characteristics are chromatic and in the shape of connexival spots. The ultrastructure of the ventral region of the head and the IX, X, and XI abdominal segments (anal tube) of the both species were described demonstrating morphological differences that can be used for diagnosis of the species.

Key words: Triatoma vandae - Triatoma williami - nymphs - Chagas disease - vectors

A subfamília Triatominae é composta atualmente por 136 táxons agrupados em 18 gêneros (Galvão et al. 2003, Forero et al. 2004). Todas as espécies são consideradas potenciais transmissoras do Trypanosoma cruzi, contudo somente algumas são vetores efetivos da doença de Chagas (Lent \& Wygodzinsky 1979, Carcavallo et al. 1999). O estudo da morfologia dos ovos e dos estádios ninfais é considerado de fundamental importância para a taxonomia dos triatomíneos. As primeiras observações foram feitas por Galliard, em 1935, que realizou um estudo morfológico comparativo dos ovos de algumas espécies em mi-croscopia óptica (MO), concluindo que diferenças na ornamentação dos ovos poderiam ser usadas para a diferenciação de espécies. Até a década de 1960, a taxonomia dos triatomíneos usava como critérios básicos, os caracteres morfológicos externos e cromáticos aliados às informações da distribuição geográfica (Lent \& Wygodzinsky 1979). A microscopia eletrônica de varredura (MEV) tem se mostrado uma importante ferramenta para uso na taxonomia, auxiliando na investigação e na análise de estruturas que permitem a diferenciação das espécies. Com a utilização desta técnica, detalhes de algumas áreas da anatomia externa dos triatomíneos vêm sendo descritos para que no futuro possam auxiliar no esclarecimento do status de espécies crípticas (Carcavallo et al. 1998a, Silva

Auxílio: CNPq, SVS-Ministério da Saúde, Chagas Disease Intervention Activities

${ }^{+}$Autor de contato. E-mail: galvao@ioc.fiocruz.br

Recebido em 9 de junho de 2005

Aceito em 31 de agosto de 2005 et al. 1999, 2000, 2002, 2003, Jurberg et al. 2002). Atualmente na sistemática dos triatomíneos têm sido utilizadas também ferramentas moleculares na tentativa de ampliar o conceito específico e, especialmente, de reconstruir a filogenia da subfamília (Hypša et al. 2002, Galvão 2003, Schaefer 2003, Paula et al. 2005) entretanto, os caracteres morfológicos e morfométricos permanecem como o ponto de partida para os estudos sistemáticos.

Triatoma williami foi descrita em 1965 por Galvão, Souza e Lima, baseada em espécimes capturados em uma fazenda, no município de Piranhas, no estado de Goiás. É uma espécie invasora do peridomicílio e domicílio (Carcavallo et al. 1998b) e até o momento seu habitat silvestre é desconhecido. Triatoma vandae foi descrita por Carcavallo et al. (2002), a partir de espécimes silvestres e sua biologia e ecologia são desconhecidas (Noireau et al. 2002). As duas espécies estão incluídas no "complexo $T$. oliveirai" que, atualmente, é composto por nove espécies encontradas nas regiões Centro-Oeste e Sul do Brasil (Galvão et al. 2001, Carcavallo et al. 2002).

O objetivo do presente trabalho foi caracterizar ovos e ninfas de $T$. vandae e $T$. williami, comparar sua morfologia, através de MO e MEV e identificar as possíveis diferenças a serem utilizadas na diagnose das espécies.

\section{MATERIAIS E MÉTODOS}

As espécies estudadas foram provenientes de colônias mantidas no insetário do Laboratório Nacional e Internacional de Referência em Taxonomia de Triatomíneos do Instituto Oswaldo Cruz, segundo o protocolo CEUA no -0014-00.

Para o estudo em MO e MEV, foram utilizados espécimes de colônias oriundas dos municípios de Goiânia, GO (T. williami) e Itiquira, MT (T. vandae). Para as observações em MO foram utilizados dois ovos e duas ninfas de cada estádio por espécie. O óperculo dos ovos foi destacado 
e montado entre lâmina e lamínula com fenol. As ninfas recém-eclodidas foram sacrificadas em baixa temperatura com a finalidade de conservar suas características morfológicas e sua coloração. Após as observações dos aspectos cromáticos, as ninfas foram montadas em lâminas e desenhadas a seco, com auxílio de uma câmara clara acoplada a um microscópio estereoscópico Wild M5. Os ovos fragmentados foram montados entre lâmina e lamínula com álcool e desenhados em microscópio biológico Wild M20. Para a análise em MEV foram utilizados três ovos e três ninfas de cada estádio. O material foi fixado com fita dupla face em suportes metálicos com 1,2 cm de diâmetro. Devido ao pequeno diâmetro dos suportes, as ninfas de $5 \underline{0}$ estádio foram cortadas na região cefálica e fixadas com a face ventral exposta. Em seguida todo o material foi metalizado com ouro, sendo posteriormente analisado de forma comparativa no microscópio eletrônico de varredura, Zeiss, modelo DSM 940 e no microscópio eletrônico de varredura SEM Leo 430 VP. As imagens foram digitalizadas e processadas no programa Adobe Photo Shop 6.0.

\section{RESULTADOS}

\section{Descrição}

\section{Triatoma vandae} Ovo

Coloração esbranquiçada após a postura, chegando ao rosa-salmão quando prestes a eclodir. Comprimento total médio de 2,2 $\pm 0,04 \mathrm{~mm}$. Relação diâmetro/largura máxima do opérculo 1:0,7. Exocório do opérculo e corpo ornamentados por áreas poligonais (hexagonais e pentagonais). Corpo constituído por células contendo pontuações e fissuras maiores do que as do opérculo, sendo essas ornamentadas apenas por fissuras (Fig. 1).

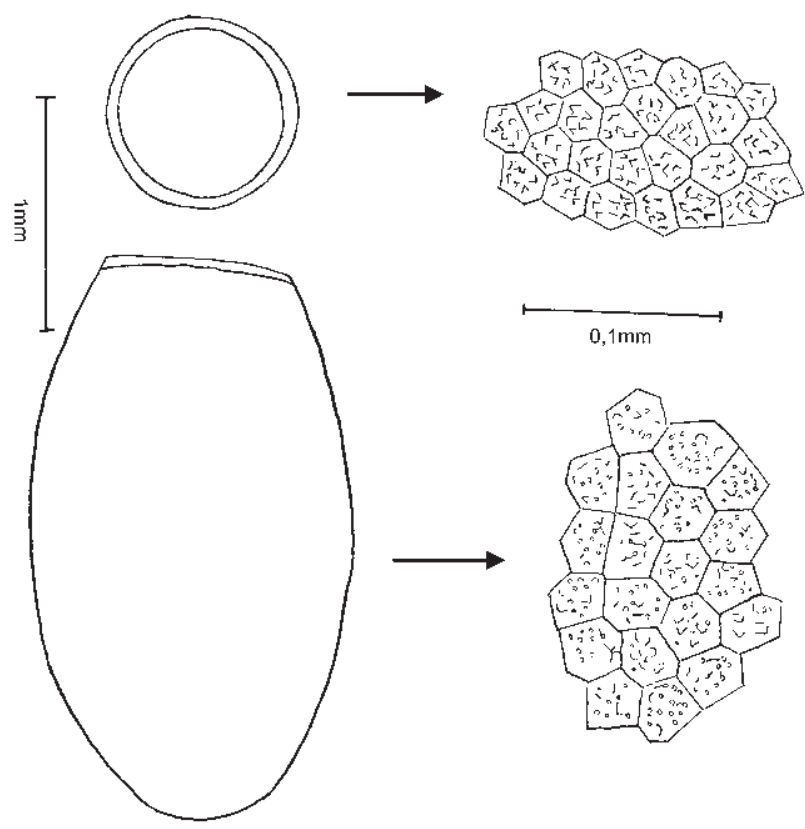

Fig. 1: Triatoma vandae Carcavallo, Jurberg, Rocha, Galvão, Noireau \& Lent, 2002. Desenho do ovo e opérculo vistos em microscopia óptica.
Pode-se observar em MEV o opérculo unido ao corpo, apresentando uma modificação gradativa da ornamentação das células que formam o exocório. Células do corpo com porosidade visivelmente maior do que as do opérculo, cujos poros são menos profundos e às vezes ausentes (Fig. 2 a-d).

Ninfas

1o estádio (Fig. 3) - Comprimento total 4,1 $\pm 0,10$ $\mathrm{mm}$. Coloração castanho-escuro, com cerdas implantadas em tubérculos setíferos, desde porção mediana da região anteocular até a sutura pós-ocular. Corpo piloso. Suturas cefálicas dorsais pós-oculares convergentes formando um "V" e prolongando-se até o $2^{\circ}$ segmento abdominal. Tegumento da cabeça em vista dorsal de aspecto irregular, pilosidade presente na região mediana dorsal (fronte) e nos bordos laterais. Jugas de ápices arredondados atingindo uma pequena porção do $1^{\underline{o}}$ segmento antenal. Presença de 1+1 faixas menos granulosas na região da sinlipsis separadas por alguns tubérculos que se fundem na altura da sutura pós-ocular. Olhos compostos negros, constituídos por omatídeos afastados uns dos outros, contendo uma área póstero-inferior lisa e sem omatídeos. Proporção entre a região pós-ocular e a anteocular de 1:2,5. Proporção entre a sinlipsis e a região ocular de 1:1,6. Antenas tetrarticuladas, inseridas lateralmente em tubérculos localizados no limite do terço anterior da cabeça, apresentando uma protuberância que contém uma cerda no bordo lateral. Coloração mais clara nos dois primeiros segmentos e na metade apical do $4^{0}$ segmento. Cerdas antenais com maior densidade nos $2 \underline{\underline{0}}$ e $3 \underline{\underline{o}}$ segmentos, especialmente nos bordos laterais. Proporções entre os artículos antenais: 1:2,0:2,6:3,0. Rostro triarticulado, retilíneo com o 3 o segmento em repouso, atingindo o bordo anterior do proesterno, de coloração menos intensa do que a da cabeça. Proporções entre os segmentos de 1:2,3:0,8. Tórax ornamentado dorsalmente por poucas cerdas implantadas em tubérculos setíferos com maior intensidade no metanoto. Pronoto trapezoidal, castanho-escuro dor-salmente; dividido em duas partes iguais por uma linha mediana longitudinal de coloração mais clara, tubérculos discais de coloração mais clara visíveis. Mesonoto de coloração negra, formado por $1+1$ placas retangulares, dividido por uma faixa membranosa dorsal, com os bordos laterais e inferior irregulares de coloração mais clara. Metanoto de coloração negra, formado por 1+1 placas retangulares de bordos internos retos e bordos externos superiores com 1+1 projeções arredondadas. Pernas apresentando coxas, trocânteres e a porção mediana basal dos fêmures mais claros do que as tíbias e os tarsos. Fêmures medianos e posteriores com 3+3 tubérculos setíferos na região inferior. Abdome castanho-claro, ornamentado por tubérculos setíferos em fileiras paralelas por toda a extensão do segmento; $8^{\circ}$ e e $9 \underline{0}$ urotergitos com $1+1$ placas escuras.

$2^{\circ}$ estádio (Fig. 4) - Comprimento total 6,4 $\pm 0,83 \mathrm{~mm}$. Coloração castanho-escuro, apresentando cerdas implantadas em tubérculos setíferos em maior quantidade nos bordos laterais da região anteocular, contendo $1+1$ linhas paralelas na região mediana dorsal. Segmentos torácicos ornamentados com tubérculos setíferos, ângulos discais visíveis no pronoto. Pronoto e mesonoto divididos por uma 
faixa membranosa mais clara, contendo $1+1$ áreas glabras centrais no bordo posterior do $2 \underline{\mathrm{O}}$ ao $7 \underline{\mathrm{O}}$ tergito. Os fềmures apresentam uma região anelar mais escura na região distal e as tíbias mais claras. Manchas conexivais a partir do $2 \underline{\mathrm{o}}$ tergito; $1+1$ placas quitinizadas no bordo superior do 8 o tergito e $1+1$ nos bordos laterais do 90 tergito. Proporção média entre a região pós-ocular e a anteocular de 1:1,9. Proporção entre a sinlipsis e a região ocular de 1:1,4. Os artículos antenais com proporções médias de 1:2,5:3,1:3,6. Rostro com as seguintes proporções médias: 1:3,0:1,3.

3 o estádio (Fig. 5) - Comprimento total $9 \pm 0,37 \mathrm{~mm}$. Coloração castanho-escuro; cabeça com o tegumento granuloso contendo cerdas inseridas em tubérculos setíferos 1+1 linhas paralelas centrais na região mediana dorsal. Protórax com $2+2$ áreas de aspecto reniforme e 1+1 no mesotórax, nos bordos posteriores laterais $1+1$ áreas glabras claras. Uma faixa clara no bordo inferior do mesotórax. Antenas negras, exceto na metade apical do $4^{\mathrm{O}}$ segmento.
No abdome, $1+1$ áreas glabras na região central do 10 ao 5 o tergitos e $1+1$ placas laterais no bordo inferior do $9^{\circ}$ tergito. Apresenta entre a região pós-ocular e a anteocular proporção de 1:2,8 e entre a sinlipsis e a região ocular de 1:1,6. Artículos antenais com as proporções médias de:1:2,9:3.0:3,3. Proporções médias entre os segmentos do rostro de 1:3,3:1,2.

4o estádio (Fig. 6) - Comprimento total 12,5 $\pm 0,44$. Coloração castanho-escuro, tórax negro. Apresenta aumento no número de tubérculos setíferos nos bordos laterais da cabeça, mantendo $1+1$ linhas paralelas na região mediana dorsal até a sutura pós-ocular. Jugas de ápices triangulares. Pronoto com tubérculos discais visíveis e 1+1 áreas glabras circundadas pelo tegumento granuloso, o mesmo ocorrendo no mesotórax com $1+1$ áreas de aspecto reniforme. Tecas alares evidenciadas; as do $1 \underline{0}$ par atingem a porção média do metatórax e as do $2^{\underline{o}}$ atingem o $1^{\mathrm{o}}$ segmento abdominal. As pernas apresentam na porção
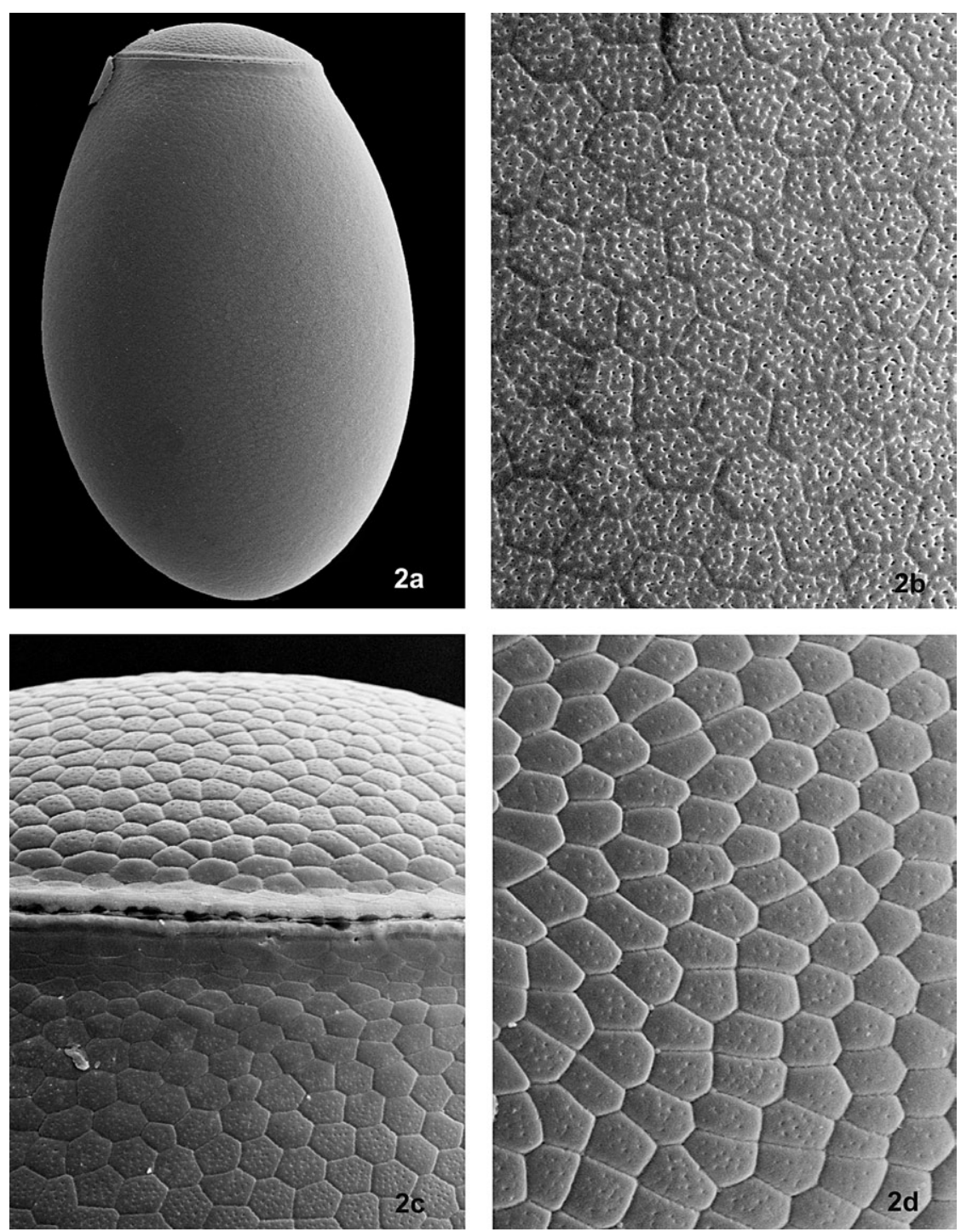

Fig. 2: Triatoma vandae Carcavallo, Jurberg, Rocha, Galvão, Noireau \& Lent, 2002. Ovo visto através de microscopia eletrônica de varredura - a: vista geral (133×); b: detalhe da superfície do opérculo (1.000×); c: detalhe do bordo superior e opérculo (790×); d: detalhe da superfície do opérculo (1.000×). 


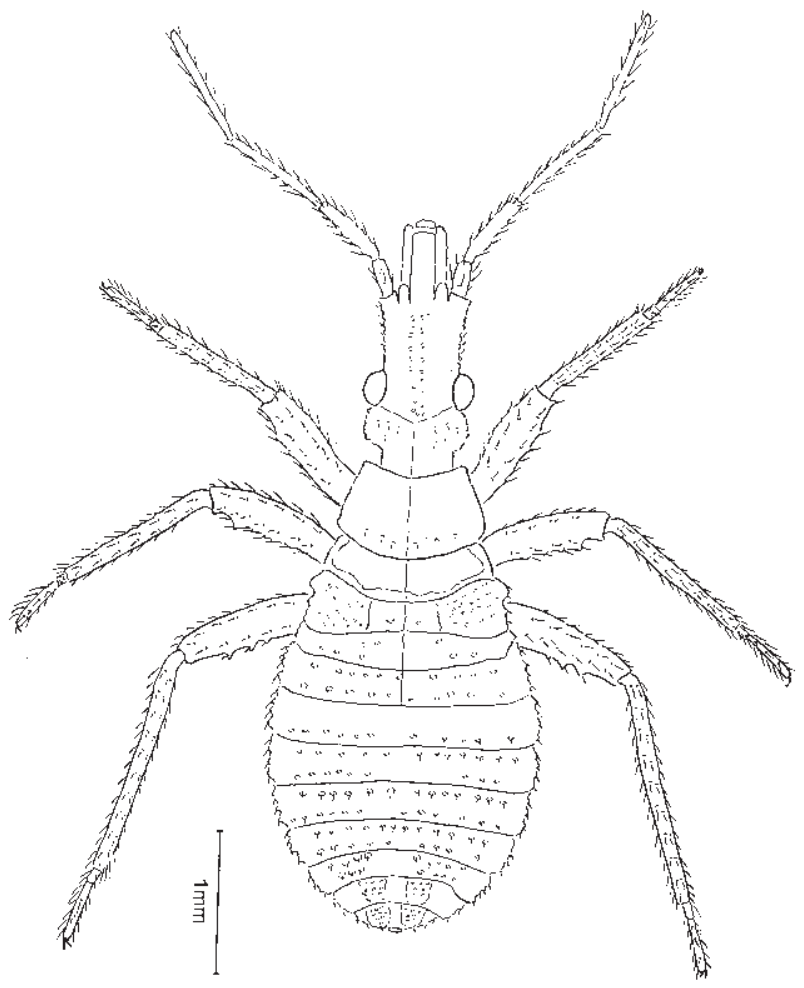

Fig. 3: Triatoma vandae Carcavallo, Jurberg, Rocha, Galvão, Noireau \& Lent, 2002. Ninfa de 1을 estádio, vista dorsal.

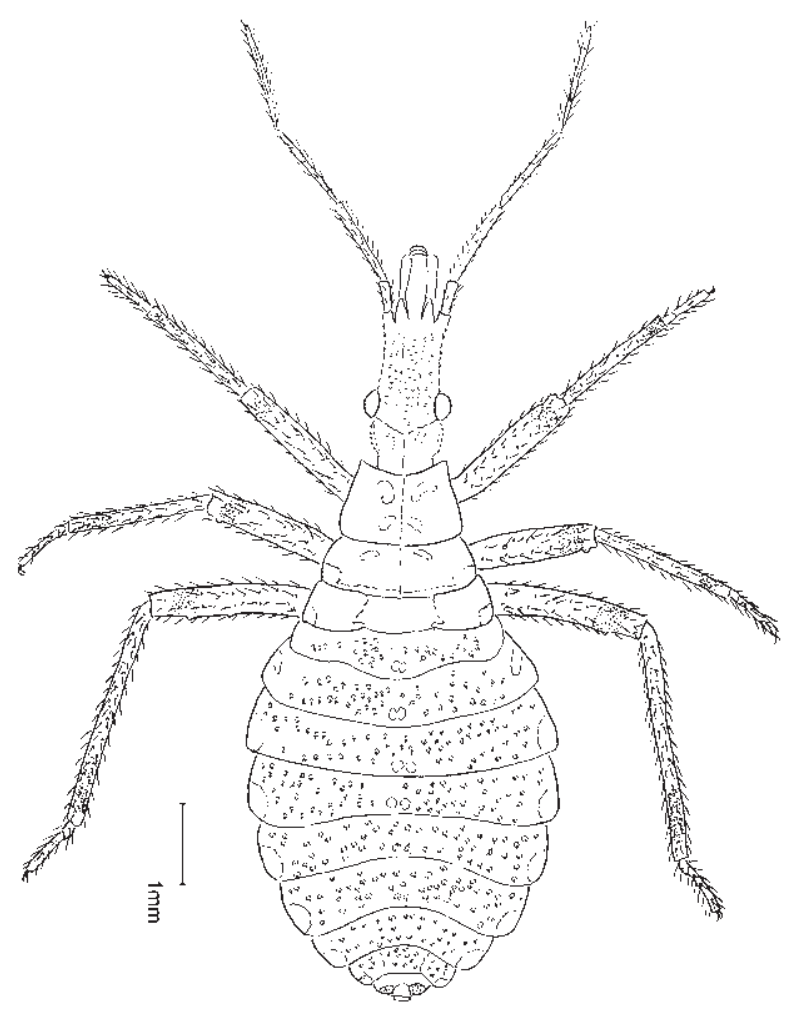

Fig. 5: Triatoma vandae Carcavallo, Jurberg, Rocha, Galvão, Noireau \& Lent, 2002. Ninfa de 3 o estádio, vista dorsal.

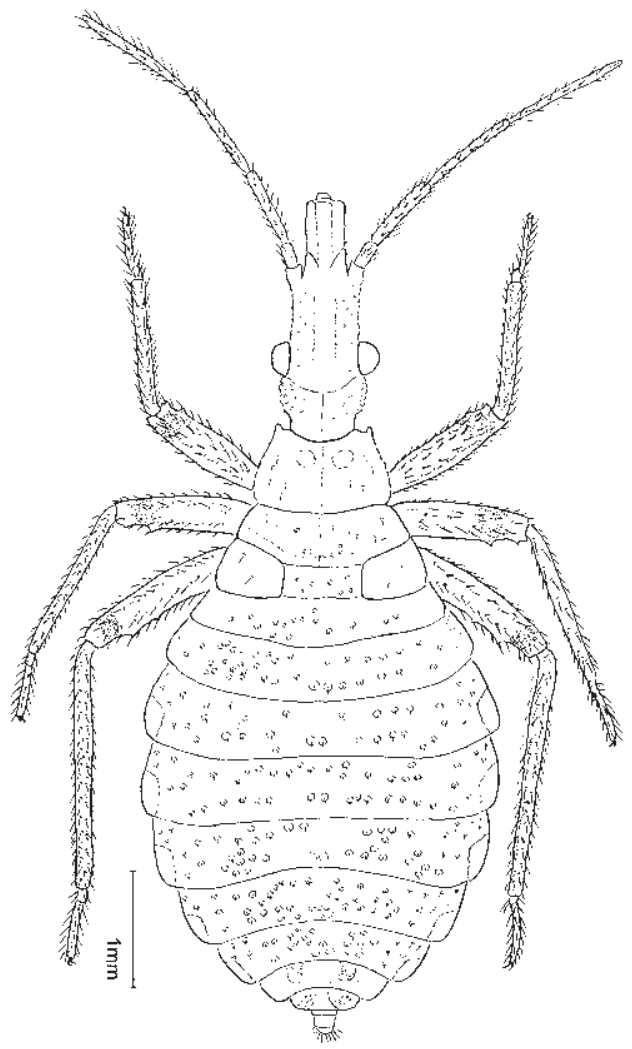

Fig. 4: Triatoma vandae Carcavallo, Jurberg, Rocha, Galvão, Noireau $\&$ Lent, 2002. Ninfa de $2^{\underline{O}}$ estádio, vista dorsal.

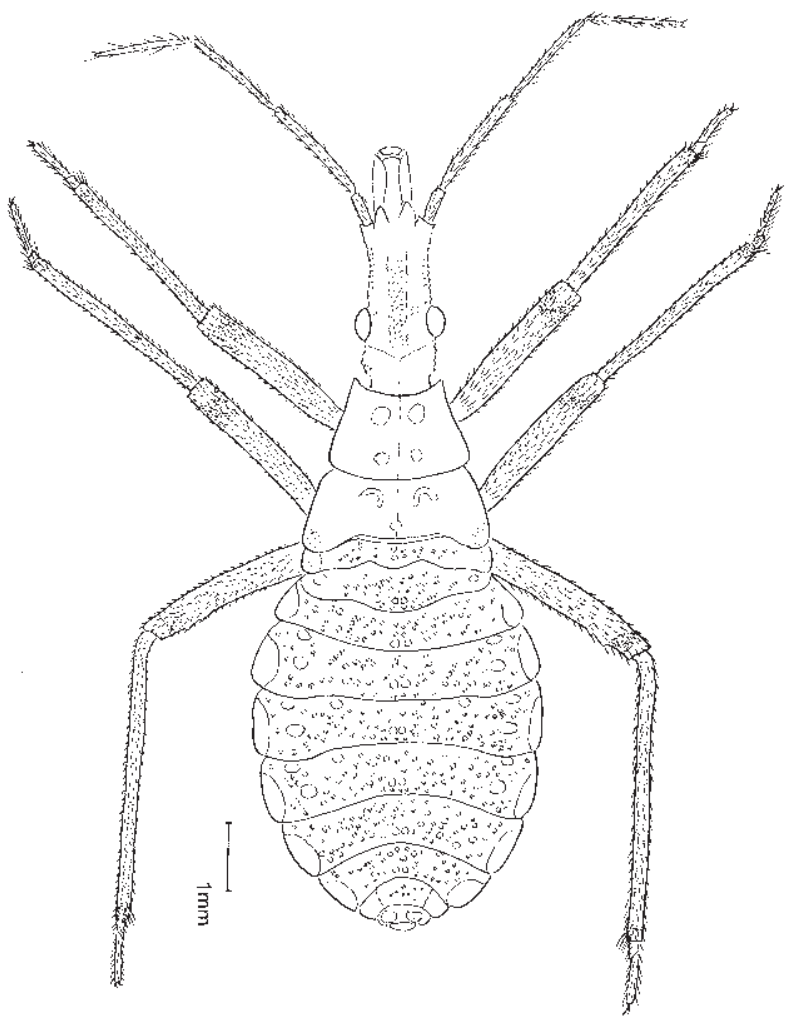

Fig. 6: Triatoma vandae Carcavallo, Jurberg, Rocha, Galvão, Noireau \& Lent, 2002. Ninfa de $4^{\circ}$ estádio, vista dorsal. 
terminal dos fêmures e tíbias um anel de coloração mais clara. $\mathrm{O}$ abdome encontra-se mais ornamentado, com $1+1$ áreas glabras do 10 ao 60 tergito e $1+1$ placas retangulares no 9으 tergito. Apresenta entre a região pós-ocular e a anteocular proporção média de 1:3 e entre a sinlipsis e a região ocular 1:1,6. Artículos antenais com as seguintes proporções médias: 1:3,8:3,3:3,4. Rostro com proporções médias de 1:3,2:1,1.

5o estádio (Fig. 7) - Comprimento total 19,3 $\pm 0,57$ $\mathrm{mm}$. Coloração castanho-escuro, clípeo unilobado e jugas com os ápices de formato triangular, 1+1 áreas glabras acima das protuberâncias de surgimento dos ocelos. Os três primeiros e a porção basal do $4^{\mathrm{O}}-$ segmento antenal de coloração negra. Tórax negro com os ângulos laterais de coloração mais clara e tubérculos discais visíveis. No mesotórax, uma pequena porção da faixa clara do bordo inferior presente e uma área glabra central. $\mathrm{O}$ abdome mostra manchas conexivais, $1+1$ áreas glabras no $1^{\underline{0}}$ segmento, uma área glabra do $2^{\circ}$ ao $6^{\circ}$, e $2+2$ áreas circulares escuras no bordo inferior no $9 \underline{0}$ segmento abdominal. Apresenta entre a região pós-ocular e a anteocular proporção média de 1:2,9 e proporção entre a sinlipsis e a região ocular de 1:1,6. Artículos antenais com as seguintes proporções médias: 1:3,8:3,1:2,6. Rostro com as proporções médias de $1: 2,4: 0,9$.

A análise $\mathrm{MEV}$ da região inter-ocular ventral permite visualisar nas ninfas de 1o estádio uma diferenciação do tecido reticular logo abaixo dos olhos compostos e algumas papilas (Fig. 8a). No 3ํㅡ e 5oㅡ estádios esta estrutura se

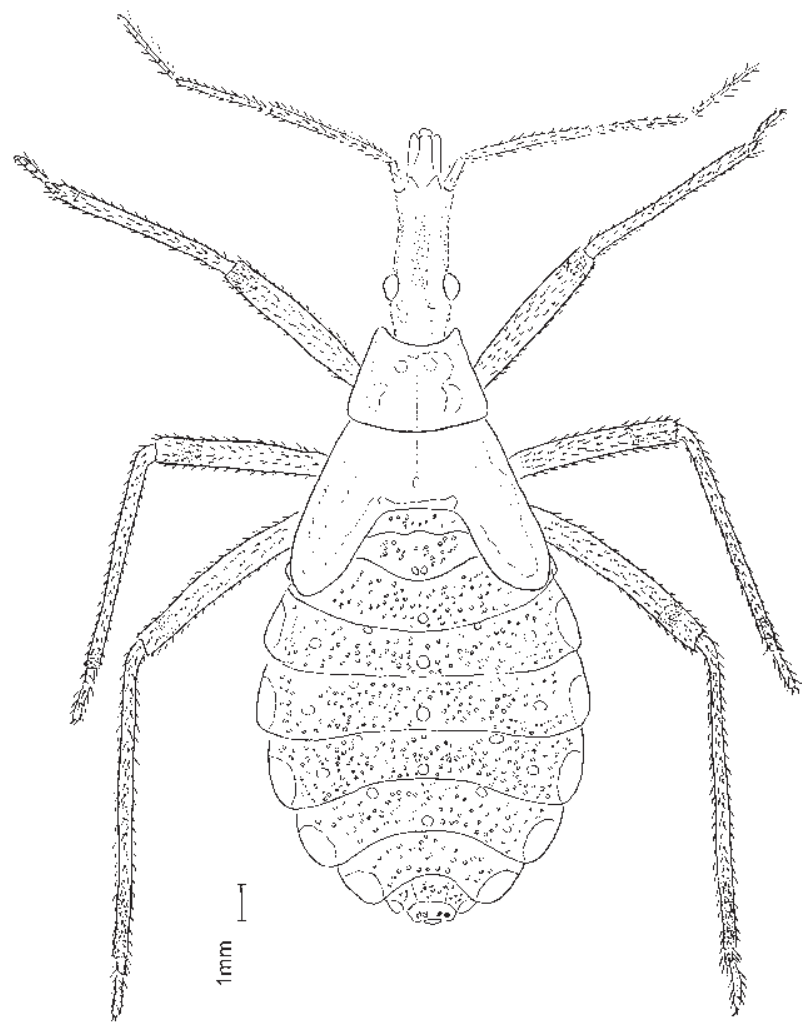

Fig. 7: Triatoma vandae Carcavallo, Jurberg, Rocha, Galvão, Noireau \& Lent, 2002. Ninfa de 5o estádio, vista dorsal.
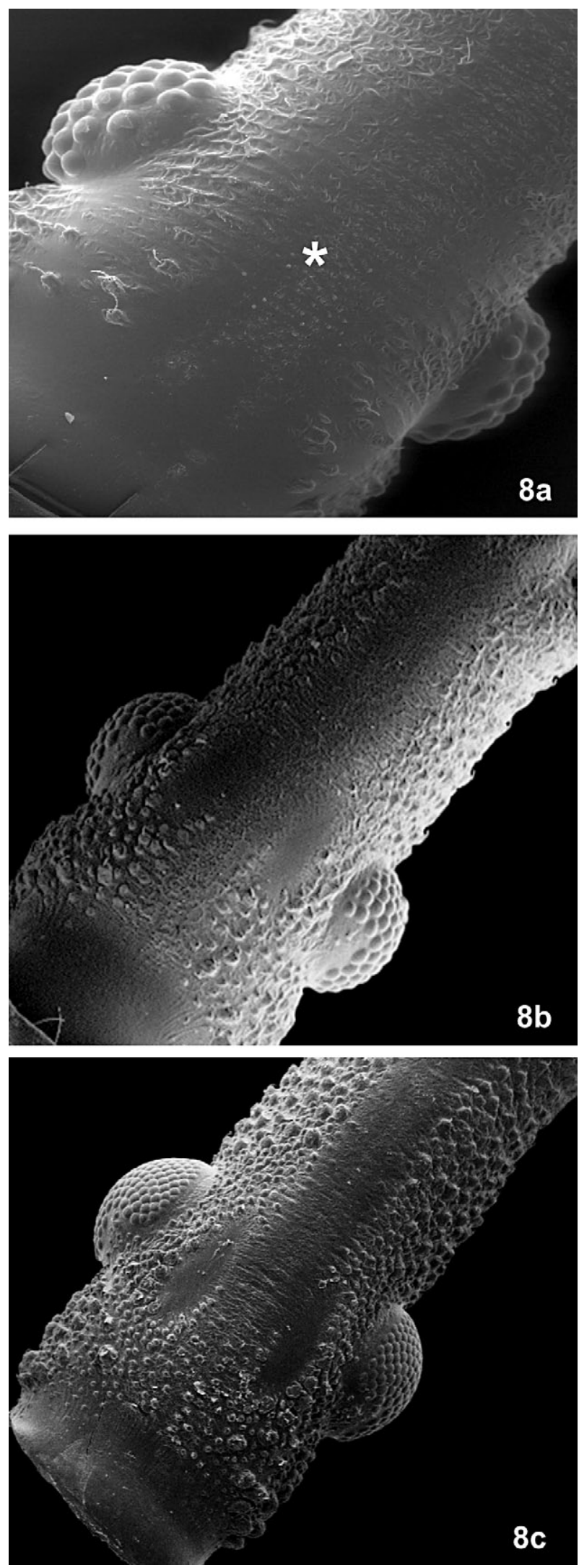

Fig. 8: Triatoma vandae Carcavallo, Jurberg, Rocha, Galvão, Noireau \& Lent, 2002 - Região inter-ocular ventral das ninfas de 1o estádio- a; $2^{\circ}$ estádio - b: 3o estádio - c. $140 \times ; 80 \times ; 70 \times$. 
apresenta com o formato ovalar e circundada por papilas (Fig. 8b,c). A análise por MEV dos últimos segmentos abdominais caracteriza-se por apresentar nas ninfas de $1 \underline{0}$ estádio o X segmento também de forma anular, notandose a presença marcante de quatro cerdas grandes, sendo duas na região mediana e duas na região posterior e com algumas cerdas pequenas espalhadas aleatoriamente (Fig. 9a). Em maior aumento, notam-se com detalhes os grânulos da região interna do $\mathrm{X}$ segmento que se exterioriza para a borda deste segmento (Fig. 9b). No XI segmento, visualizam-se diferentes tipos de sensilas (Fig. 9a, b, d). No 3 o estádio, observam-se os espiráculos respiratórios no $7 \underline{0}$ e $8^{\circ}$ segmentos abdominais e uma diferenciação do tegumento em toda a extensão dos segmentos (Fig. 9c-f).
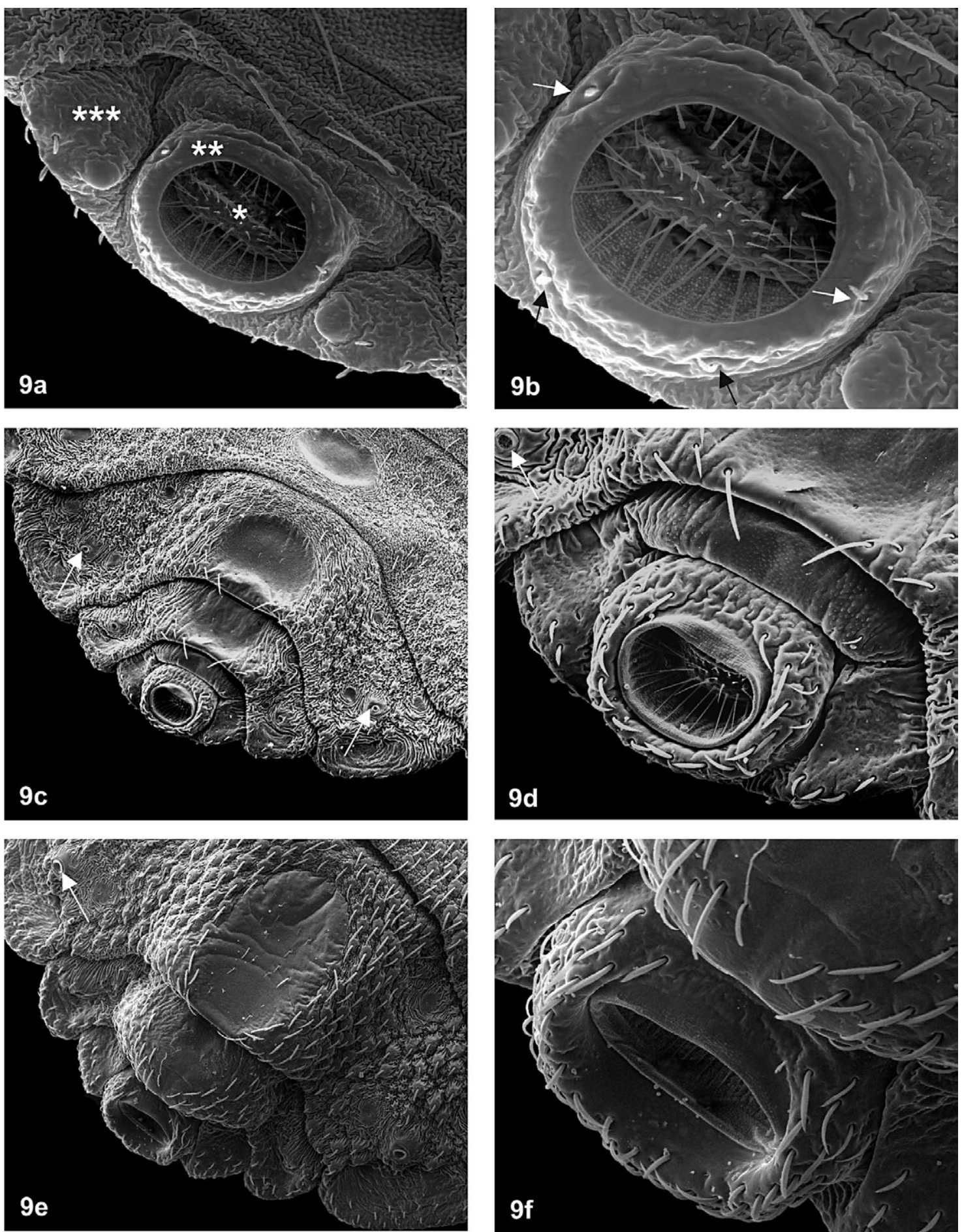

Fig. 9: Triatoma vandae Carcavallo, Jurberg, Rocha, Galvão, Noireau \& Lent, 2002. Últimos segmentos abdominais. Nos 1으 (a, b; 200×; 350×), 2을 (c, d; 100×; 380×) e 3o (e, f; 100×; 570×) estádios ninfais. Segmentos: VIII***, IX** e X*. Espiráculos respiratórios: setas. 


\section{Triatoma williami \\ Ovos}

Apresentam a proporção média de 1:1,9 com relação ao diâmetro do opérculo e a largura máxima e o comprimento total de 2,1 $\pm 0,05 \mathrm{~mm}$. Em MO, o opérculo apresenta pontuações aleatórias distribuídas em células hexagonais e pentagonais, corpo formado por células maiores hexagonais justapostas e outras menores, com pontuações aleatórias (Fig. 10). Através da MEV pode-se observar que são menores e as pontuações aleatórias distribuídas em células hexagonais e pentagonais do opérculo, em menor quantidade do que as do corpo,e possuem um formato mais abaulado (Fig.11a, b, c).

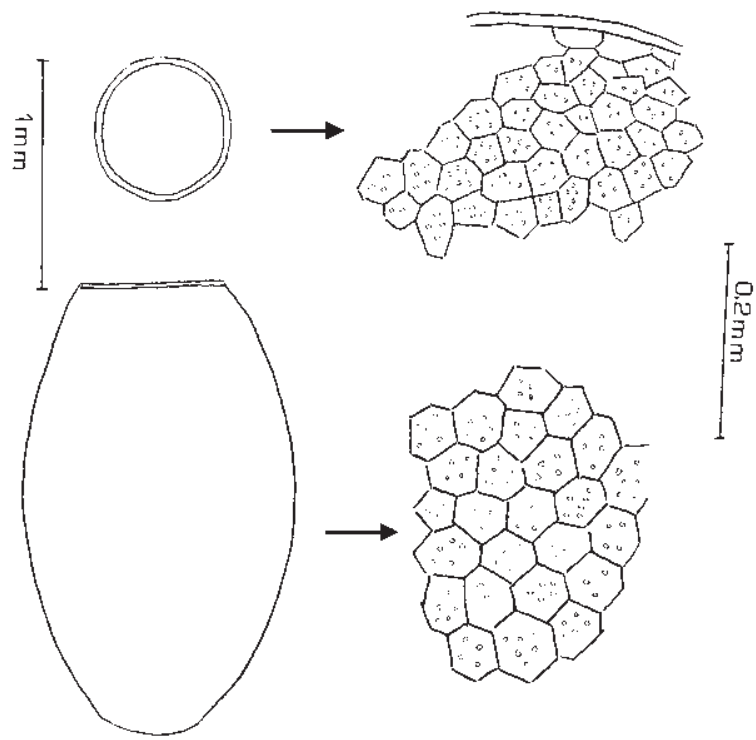

Fig. 10: Triatoma wiliami Galvão, Souza \& Lima, 1965. Ovo e opérculo vistos em microscopia óptica.
Ninfas

1 을 estádio (Fig.12) - Comprimento total 3,2 $\pm 0,14 \mathrm{~mm}$. Coloração geral castanho-claro. Cabeça em vista dorsal apresenta o tegumento que recobre toda sua extensão de aspecto granular, presença de tubérculos setíferos distribuídos aleatoriamente, com maior concentração nos bordos laterais, nas regiões ante e pós-ocular. Clípeo unilobado, jugas de ápices arredondados atingindo a região basal do 10 segmento antenal. Sulco pós-ocular bem demarcado seguindo em direção ao tórax. Em vista ventral, apresenta inúmeros tubérculos setíferos em toda sua extensão, exceto em uma faixa larga na região inter-ocular e menor quantidade numa faixa longitudinal que se estende da juga até o pescoço. Olhos compostos negros, constituídos por omatídeos circulares afastados uns dos outros, contendo uma área póstero-inferior lisa e sem omatídeos. Apresenta entre a região pós-ocular e a anteocular a proporção média de 1:2,4 e proporção entre a sinlipsis e a região ocular de $1: 1,6$. Antenas tetrarticuladas, inseridas em tubérculos laterais localizados no limite do terço anterior da cabeça; possui em suas extremidades laterais uma protuberância saliente contendo uma cerda grossa em seus ápices. Coloração castanho-escura nos três primeiros segmentos incluindo a metade basal do $4^{\circ}$ segmento, cuja metade apical caracteriza-se pela coloração castanho-claro com sensilas longas inseridas espaçadamente. Demais segmentos ornamentados por sensilas que se encontram em menor quantidade no $1^{\circ}$ segmento. Artículos antenais com as proporções médias de: 1:2,3:3,3:3,7. Rostro triarticulado, retilíneo, com o $3^{\circ}$ segmento atingindo o bordo anterior do prosterno quando em repouso, de coloração menos intensa do que a cabeça. Os três segmentos encontram-se ornamentados por sensilas que aumentam em quantidade e tamanho no $3^{\circ}$ segmento. Os segmentos apresentam proporções médias de 1:2,0:1. Tórax de coloração castanho-claro, ornamentado
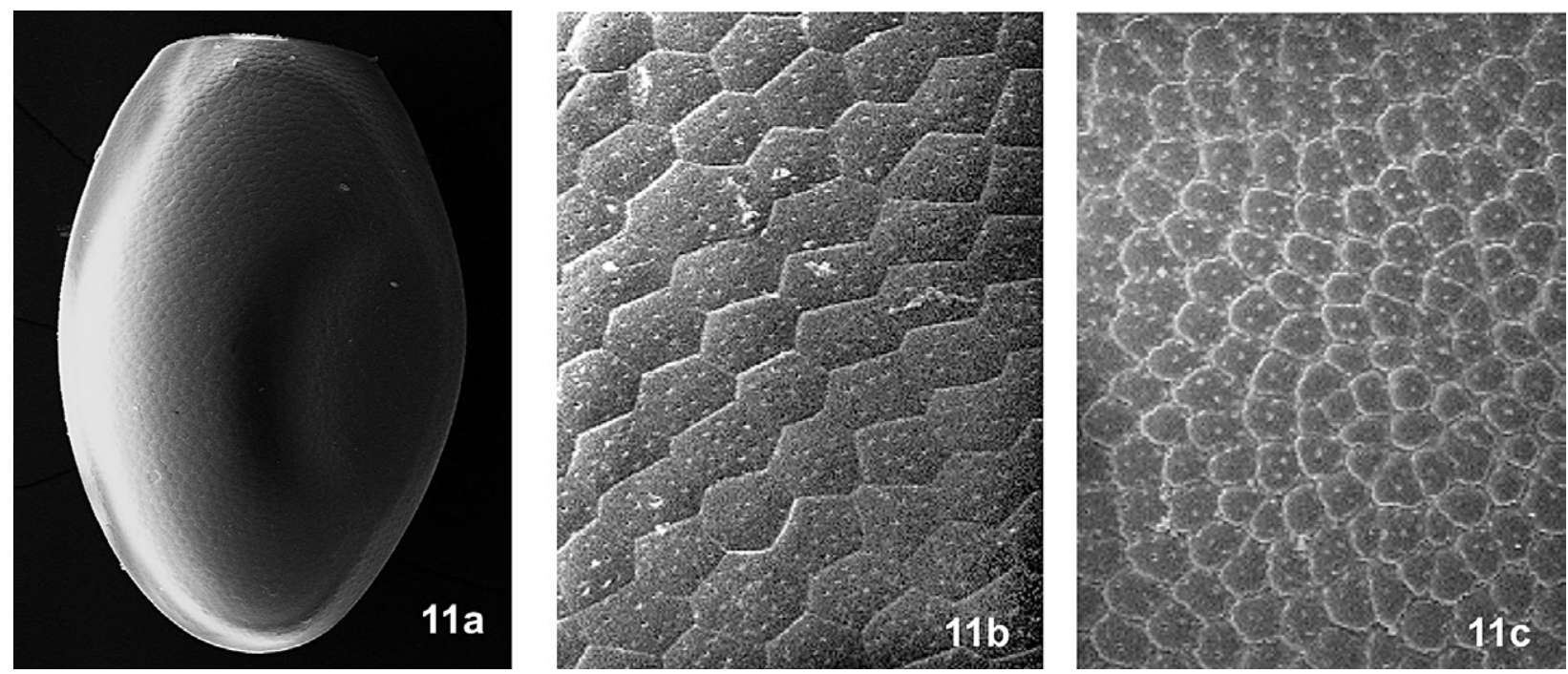

Fig. 11: Triatoma wiliami Galvão, Souza \& Lima, 1965. Ovo visto através de microscopia eletrônica de varredura - a: vista geral (133×); b: detalhe da superfície do opérculo $(1000 \times)$; c: detalhe da superfície do corpo $(1000 \times)$. 


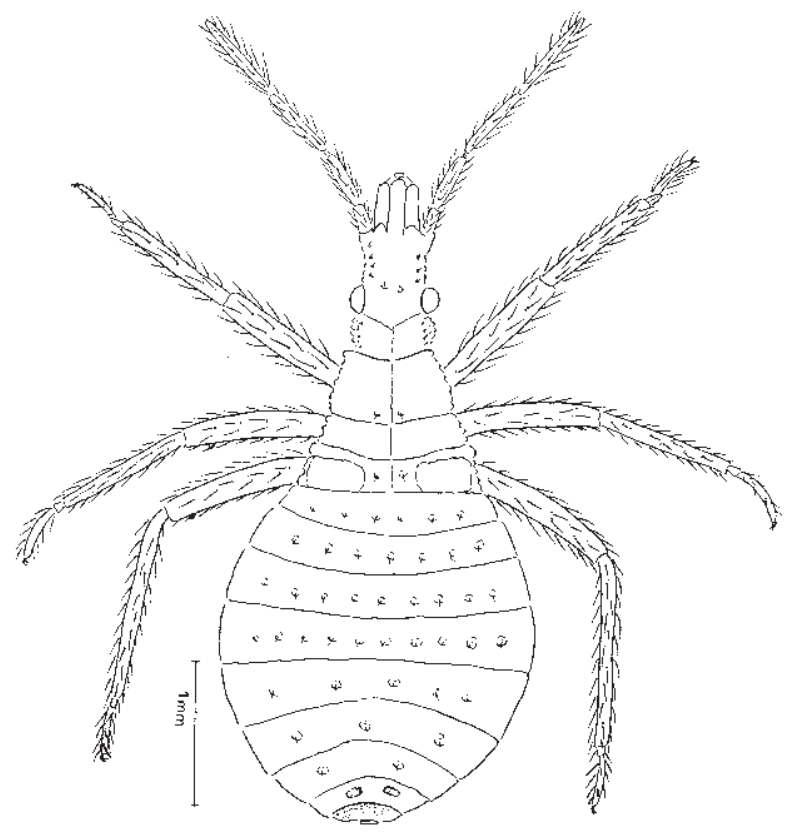

Fig. 12: Triatoma williami Galvão, Souza \& Lima, 1965. Ninfa de $1^{\circ}$ estádio, vista dorsal.

dorsalmente com poucas cerdas implantadas em tubérculos distribuídos aleatoriamente ao longo dos segmentos. Pronoto de forma trapezoidal, ornamentado lateralmente por uma faixa clara dos ângulos ântero-laterais até o limite inferior. Dorsalmente dividido em duas partes iguais por uma linha mediana longitudinal mais clara. Tubérculos discais visíveis. Mesonoto representado por $1+1$ placas retangulares; bordos laterais e inferiores delimitados por uma faixa clara lateralmente e inferiormente contendo poucos pêlos na região lateral, sendo dividido por uma faixa membranosa dorsal. Metanoto formado por $1+1$ placas retangulares menores do que o mesonoto. Pernas apresentando coxa, trocânteres, articulações entre fêmures e tíbias e os dois terços basais dos fêmures mais claros do que as tíbias e os tarsos. Abdome com coloração castanhoclaro, nítida marcação dos nove segmentos, separados por uma delicada membrana. Segmentos ornamentados por tubérculos setíferos dispostos em fileiras que se intensificam nos quatro primeiros. No $8^{\circ}$ tergito, apresenta $1+1$ placas retangulares e uma única placa ocupando quase toda porção do nono tergito.

$2^{2}$ estádio (Fig. 13) - Comprimento total 6,3 $\pm 0 \mathrm{~mm}$. Coloração castanho-escuro. Cerdas da cabeça implantadas em tubérculos setíferos na região lateral da região anteocular, em maior concentração na região mediana que se estende das jugas até a sutura inter-ocular e nas extremidades laterais nas calosidades pós-oculares. Os três segmentos torácicos encontram-se delimitados lateralmente por uma faixa clara, sendo cobertos por cerdas inseridas em tubérculos dispostos aleatoriamente. Manchas conexivais presentes a partir do $2^{\circ}$ segmento abdominal, contendo áreas glabras centrais $1+1$ do $2^{\underline{O}}$ ao $6^{-}$tergito. Apresenta entre a região pós-ocular e a anteocular proporção média de 1:2,5; proporção entre a sinlipsis e a região ocular de 1:1,5. Artículos antenais com proporções médias de 1:2,2:3,9:3,0. Rostro com proporções médias de 1:3:1,3.

3o estádio (Fig. 14) - Comprimento total 8,6 $\pm 0,19$ $\mathrm{mm}$. Coloração castanho escuro, cerdas implantadas em tubérculos setíferos da região anteocular até a calosidade pós-ocular, com maior concentração na região central onde se encontram em fileiras paralelas. Jugas de forma triangular. Protuberâncias ocelares presentes. Antenas de coloração negra nos três primeiros segmentos e nos $2 / 3$ basais do $4^{\circ}$ segmento. Tórax delimitado, lateralmente, por uma faixa clara com $1+1$ tubérculos discais. Abdome com $1+1$ áreas glabras no bordo inferior central do $1^{\circ}$ ao $5 \underline{0}$ tergitos. Apresenta entre a região pós-ocular e a anteocular a proporção média de 1:2,3 e entre a sinlipsis e a região ocular 1:1,6. Artículos antenais com proporções médias de 1:3,1:3,0:4,8. Rostro com proporções médias de 1:3,1:1,2.

40 estádio (Fig. 15) - Comprimento total 11,2 $\pm 0,37$ $\mathrm{mm}$. Coloração castanho-pardo. Cabeça ornamentada com cerdas inseridas em tubérculos com maior concentração da região anteocular até a calosidade pós-ocular. Tecas alares evidenciadas, sendo que o primeiro par atinge o bordo anterior do metatórax e o segundo atinge uma pequena porção do $1 \underline{0}$ tergito. Mesotórax com $1+1$ áreas de aspecto reniforme e ângulos discais presentes no protórax. Pernas de coloração marron, mais claras do que o corpo. Abdome com $1+1$ áreas glabras do $2^{\circ}$ ao 50 tergitos. Apresenta entre a região pós-ocular e a anteocular a proporção média de

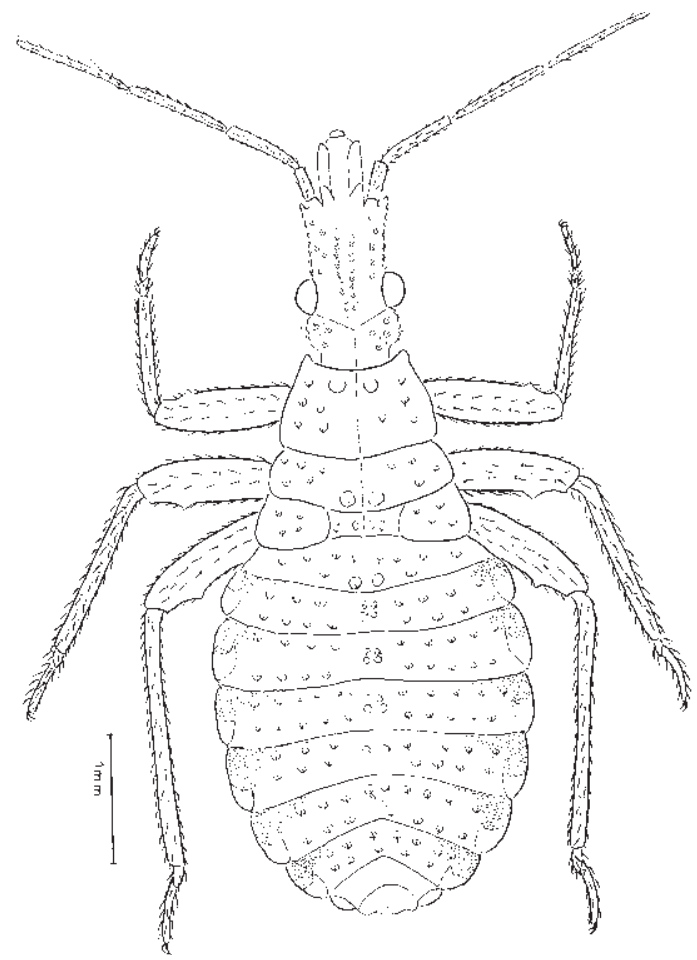

Fig. 13: Triatoma williami Galvão, Souza \& Lima, 1965. Ninfa de 2으 estádio, vista dorsal. 


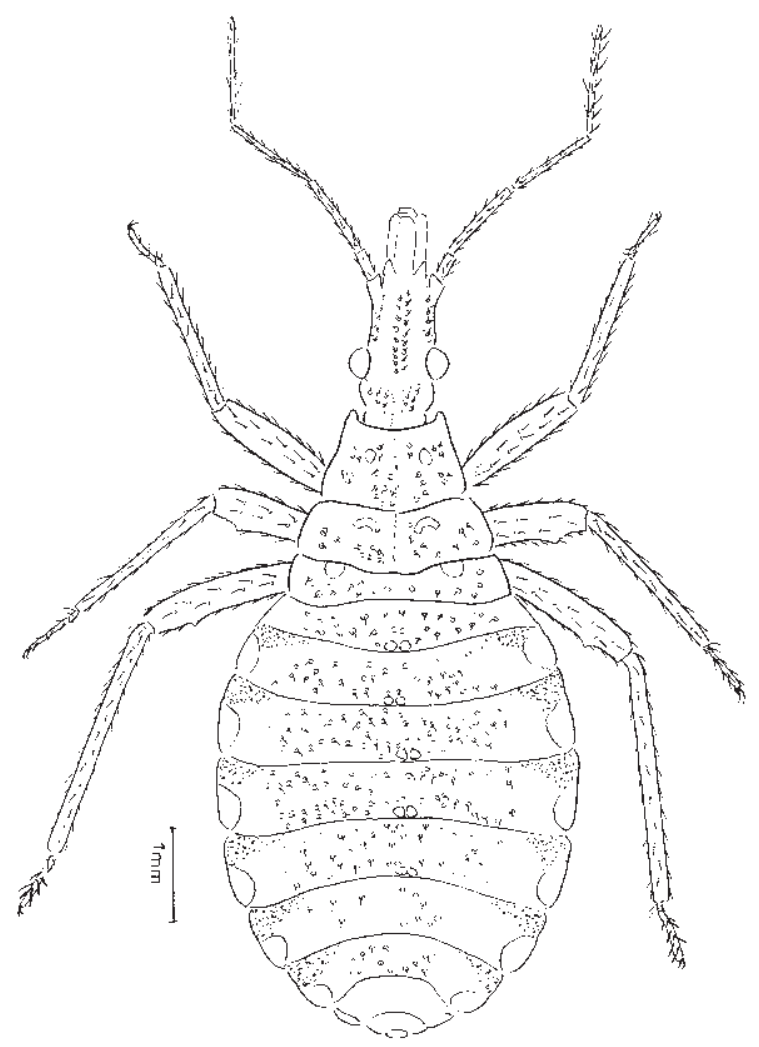

Fig. 14: Triatoma williami Galvão, Souza \& Lima, 1965. Ninfa de 3o estádio, vista dorsal.

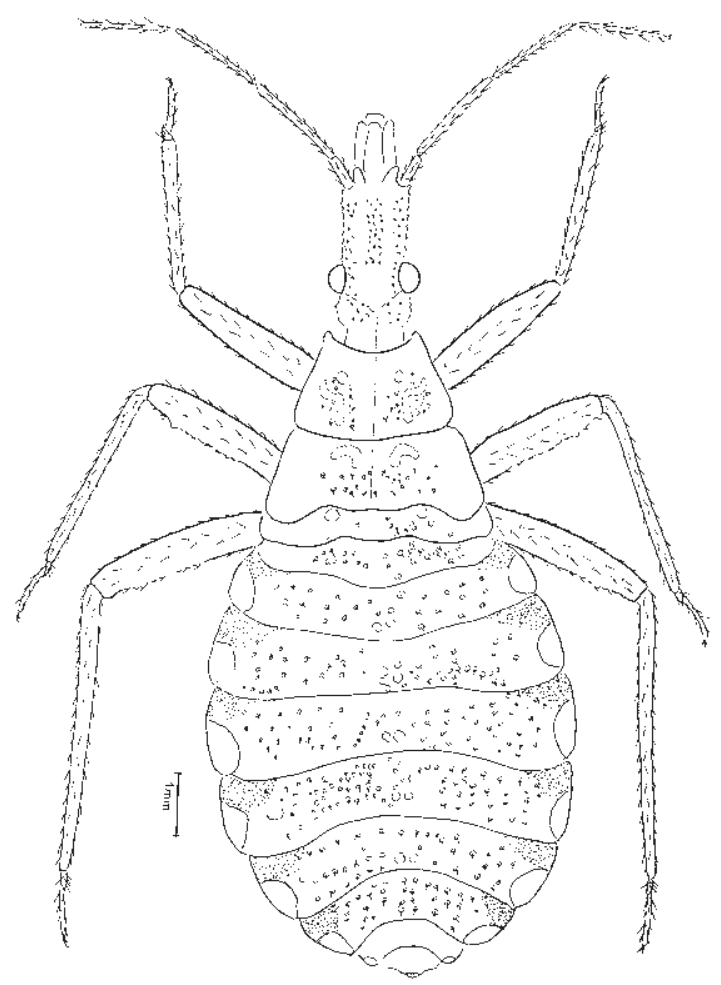

Fig. 15: Triatoma williami Galvão, Souza \& Lima, 1965. Ninfa de 40 estádio, vista dorsal.
1:2,9. Proporção entre a sinlipsis e a região ocular de 1:1,5. Artículos antenais com proporções médias de 1:3,4:3,5:3,4. Rostro com proporções médias de: 1:3,0:1,3.

5o estádio (Fig. 16) - Comprimento total 18,0 $\pm 0 \mathrm{~mm}$. Coloração parda. Cabeça contendo cerdas implantadas em tubérculos setíferos localizados nas genas, com maior concentração na faixa central que se estende das jugas até o sulco pós-ocular e aleatoriamente nas calosidades pósoculares, conferindo um aspecto granuloso a toda a cabeça. Jugas com aspecto triangular, com $1+1$ protuberâncias dorsais no ponto de surgimento dos ocelos, olhos compostos, negros, constituídos por omátideos justapostos. Três primeiros segmentos antenais e base do $4 \underline{0}$ de coloração negra. Pronoto lateralmente ornamentado com faixa clara, $1+1$ áreas de aspecto reniforme no mesotórax. Tecas alares quase atingindo o bordo inferior do $2^{\underline{o}}$ segmento abdominal. Abdome mostrando manchas conexivais contendo uma região mais clara no bordo inferior dos segmentos, com área glabra do $2 \underline{0}$ ao $6 \underline{0}$ tergitos. Apresenta entre a região pós-ocular e a anteocular a proporção média de 1:2,9. Proporção entre a sinlipsis e a região ocular de 1:1,6. Artículos antenais com proporções médias de 1:4,3;3,7:3,7. Rostro com proporções médias de 1:2,5:1,1.

Através da MEV da região inter-ocular ventral, visualizam-se, nas ninfas de 1o estádio, uma diferenciação do tecido reticular logo abaixo dos olhos compostos e algumas papilas (Fig. 17a). No 3으 e 5을 estádios, podem-se visualizar 1+1 áreas glabras ovalares próximas ao bordo interno dos olhos; a área central está recoberta por inúmeros tubérculos

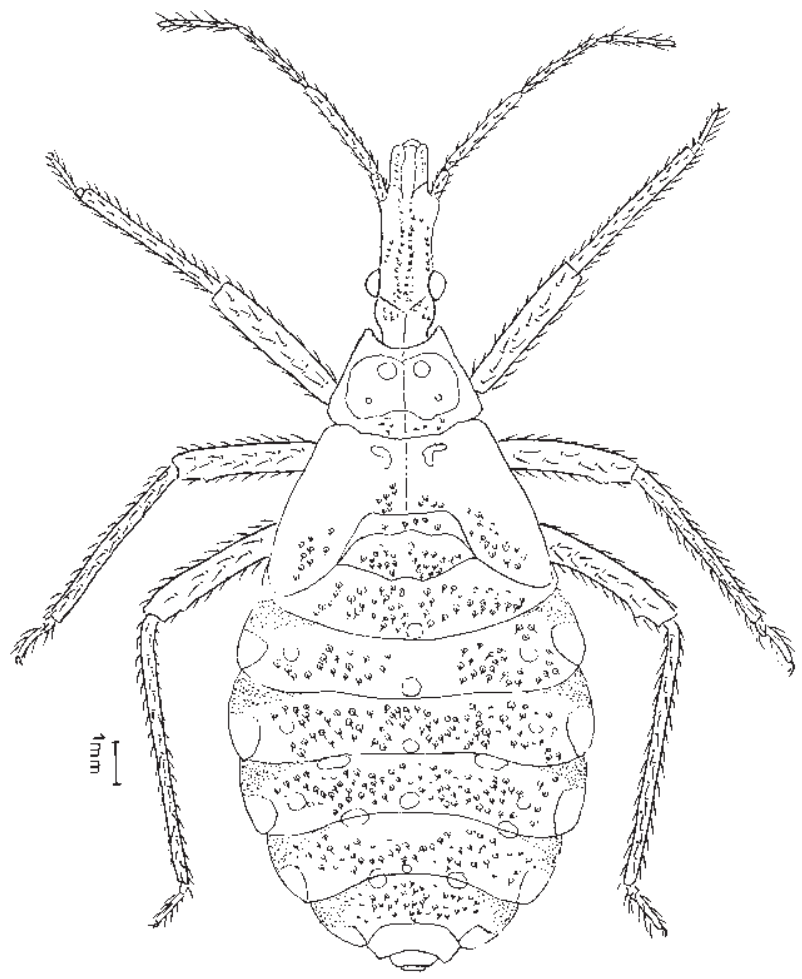

Fig. 16: Triatoma william Galvão, Souza \& Lima, 1965. Ninfa de 5으 estádio, vista dorsal. 

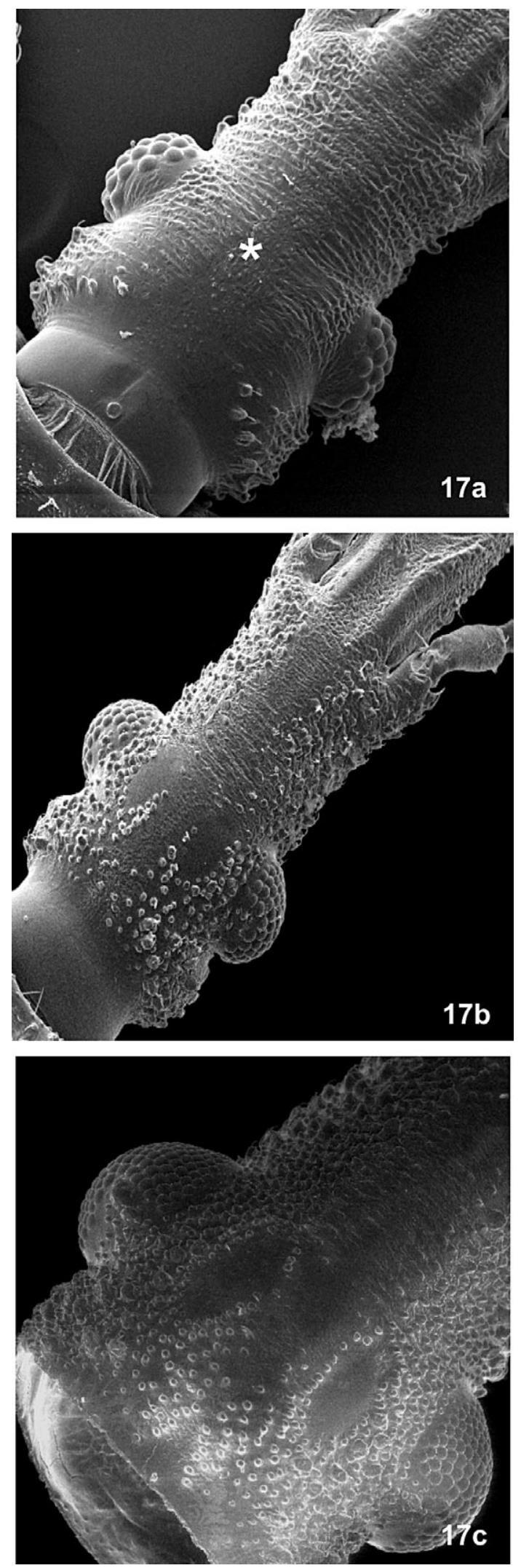

Fig. 17: Triatoma wiliami Galvão, Souza \& Lima, 1965. Cabeça: microscopia eletrônica de varredura da região ventral inter-ocular $\left(^{*}\right)$. a: ninfa de $1 \underline{0}$ estádio $(165 \times)$; b: ninfa de $3 \underline{0}$ estádio $(80 \times)$; c: ninfa de $5 \stackrel{0}{\circ}$ estádio $(50 \times)$. arredondados, menos densos do que nas áreas próximas aos bordos internos dos olhos (Fig. 17b-c). A MEV dos últimos segmentos abdominais (IX ao XI) mostra o $\mathrm{X}$ segmento de forma anular com inúmeras cerdas grossas e decumbentes ao redor da abertura (Fig. 18a, b). No IX segmento, tubérculos setíferos proeminentes com cerdas de ápice rombo e serrilhado (Fig. 18b). Nos estádios seguintes, os últimos segmentos (IX ao XI) apresentam o XI segmento ou ânus telescopando-se dentro do X segmento e mostram nos seus bordos superiores e inferiores uma série de cerdas longas e afiladas (Fig. 18b-d). O X segmento tem o seu interior constituído por um tegumento estriado transversalmente e o exterior coroado por $1+1$ fileiras de cerdas grossas decumbentes (Fig.18 e, f).

\section{DISCUSSÃO}

A importância do conhecimento dos ovos dos triatomíneos foi ressaltada por Pinto (1924) quando teve a oportunidade de descrever a morfologia e a coloração dos ovos de Triatoma brasiliensis Neiva, 1925, conseguindo diferenciá-la das outras espécies de "barbeiros" existentes no Brasil. Barata (1981) mostrou a possibilidade de empregar as estruturas e as distintas ornamentações do exócorio e opérculos dos ovos na diagnose das espécies, incluindo uma chave para identificação de dez espécies do gênero Rhodnius. Aspectos da morfologia externa e do exócorio e as dimensões dos ovos em nove gêneros de triatomíneos foram descritos por Barata (1998). Um sumário dos trabalhos dedicados à morfologia de ovos e ninfas de triatomíneos foi publicado recentemente por Galvão et al. (2005).

No presente trabalho, verificamos por MO que a superfície do exocório dos ovos de $T$. vandae apresentou células do corpo ornamentadas por pontuações e fissuras e as células do opérculo apenas por fissuras, enquanto T. williami apresentou células ornamentadas por pontuações, dispostas ao acaso no corpo e no opérculo. Estes ovos, quando observados comparativamente por MO, apresentaram características macroscópicas no seu exocório capazes de distinguir as espécies pertencentes ao mesmo complexo. Em T. matogrossensis, o exocório é formado por um sistema de linhas irregulares e curvadas (Jurberg \& Vogel 1994). Já em T. guazu, o opérculo e o corpo são formados por células ornamentadas por pequenas perfurações distribuídas ao acaso (Silva et al. 2000), enquanto T. jurbergi apresenta o opérculo ornamentado por pequenas fraturas e o corpo, além de pequenas fraturas, pontuações distribuídas ao acaso. A proporção entre o diâmetro do opérculo e a largura máxima do ovo de $T$. vandae é menor do que em $T$. williami, diferente de $T$. jurbergi e $T$. guazu que apresentam estes índices iguais entre si. Por MEV T. vandae apresenta uma porosidade visivelmente maior nas células do corpo do que as observadas em T. williami.

No presente trabalho pode-se constatar, entre outras diferenças, as relacionadas às manchas conexivais que surgem a partir do $2^{\circ}$ estádio. Em T. vandae essas manchas conexivais apresentam-se claras e definidas ocupando a metade inferior do segmento. Em T. williami, estas manchas são pouco definidas, ocupando uma parte da porção 

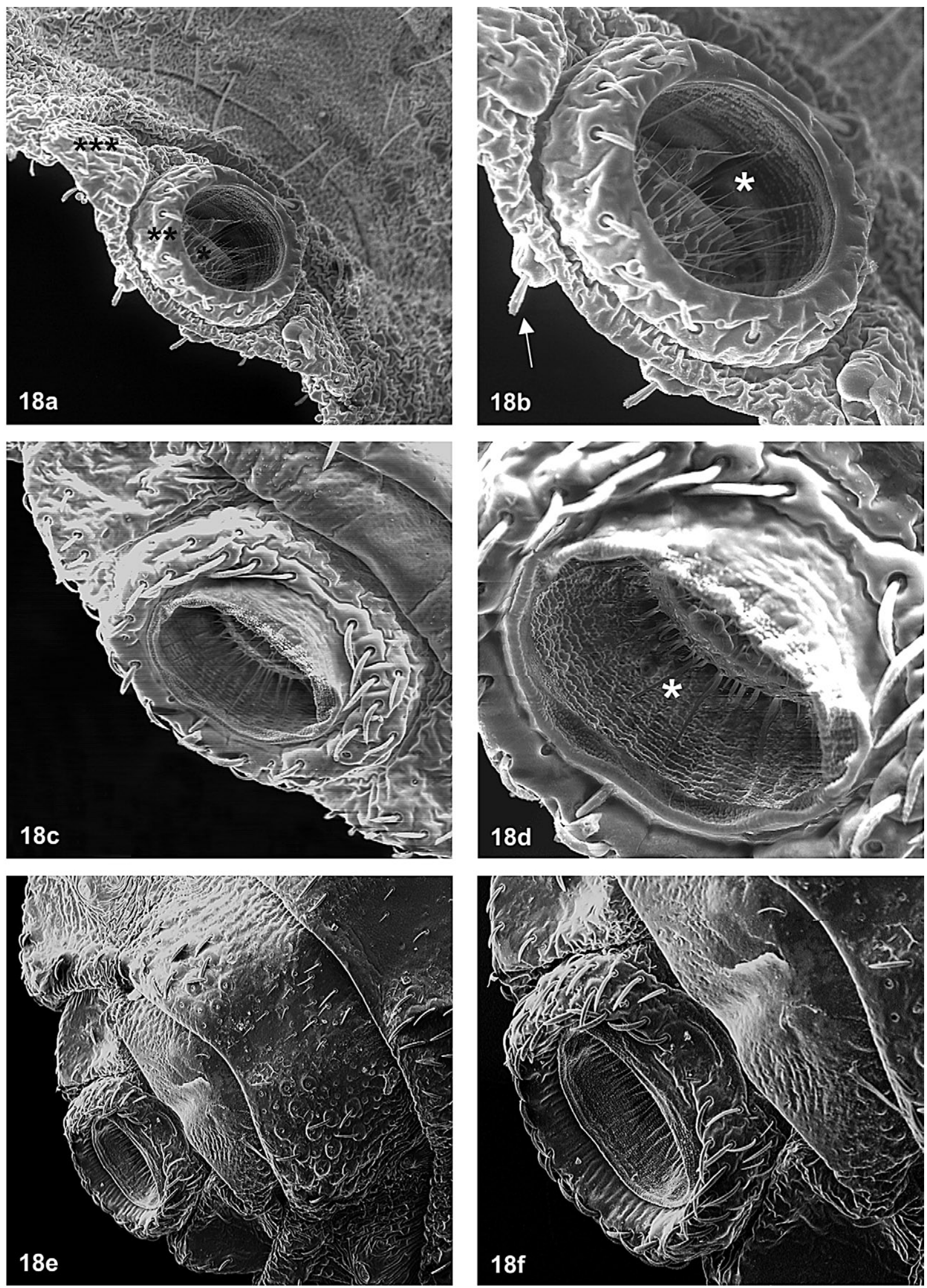

Fig. 18: Triatoma wiliami Galvão, Souza \& Lima, 1965. Vista ventral dos últimos segmentos abdominais por microscopia eletrônica de varredura.

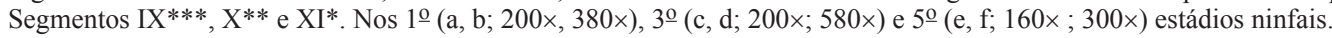


superior dos segmentos abdominais. Há também diferenças cromáticas entre as duas espécies estudadas, assim como previamente observado nas ninfas de outras espécies do complexo T. oliveirai (Jurberg \& Vogel 1994, Silva et al. 1999, 2000, 2002, 2003, Jurberg et al. 2002). Diversos autores têm buscado novos parâmetros que, associados aos apresentados por Lent e Wygodzinsky (1979), permitam avançar e tentar elaborar uma chave de identificação específica (Carcavallo et al. 1994a, b, c, 1995, GalindezGirón et al. 1998).

A análise comparativa por MEV dos últimos segmentos abdominais e da região ventral inter-ocular do $1^{0}$, $3 \underline{\text { e }} 5^{\circ}$ estádios possibilitou verificar diferenças morfológicas entre as ninfas das espécies estudadas. Com relação ao X

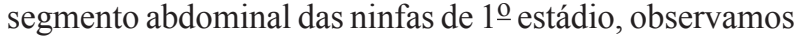
que $T$. vandae apresentou quatro cerdas grandes, sendo que duas delas na região mediana e duas na região posterior, contando ainda, com algumas cerdas pequenas espalhadas ao acaso, enquanto T. williami apresentou cerdas por toda a circunferência abdominal. Pode-se visualizar no IX segmento tubérculos setíferos proeminentes com cerdas de ápice rombo e serrilhado apenas em T. williami, característica esta não observada em T. vandae. A morfologia dos últimos segmentos abdominais das ninfas dos triatomíneos já tem sido evidenciada por vários autores (Espínola 1966, Rosa et al. 1992a, b) que definiram o futuro sexo através de sua morfologia. Carcavallo et al. (1994b, c, 1995) evidenciaram semelhanças e diferenças com valor sistemático da região óculo-ocelar das espécies conhecidas do gênero Rhodnius Stål,1859, de 11 espécies do gênero Panstrogylus Berg, 1879 e do gênero Psammolestes Bergroth, 1911. No presente trabalho observou-se que a configuração destas estruturas varia com a evolução dos estádios em $T$. vandae e T. williami. As diferenças encontradas poderão minorar as dúvidas na identificação das formas imaturas destas espécies e serem empregadas para diagnose das espécies e na organização de chaves dicotômicas para ninfas.

\section{REFERÊNCIAS}

Barata JMS 1981. Aspectos morfológicos de ovos de triatomíneos. II - Características macroscópicas e exocoriais de dez espécies do gênero Rhodnius Stål, 1859 (HemipteraReduviidae). Rev Saúde Públ São Paulo 15: 490-542.

Barata JMS 1998. Macroscopic and exocorial structures of Triatominae eggs (Hemiptera, Reduviidae). In. RU Carcavallo, I. Galíndez-Girón, J Jurberg, H Lent (eds.), Atlas of Disease Vectors in the Americas, Fiocruz, Rio de Janeiro, Vol. II, p. 409-448.

Carcavallo RU, Curto de Casas SI, Sherlock IA, Galíndez-Girón I, Jurberg J, Galvão C, Mena Segura CA. 1999. Geographical distribution and altilatitudinal dispersion. In RU Carcavallo, I Galindz-Girón, J Jurberg, H Lent (eds.), Atlas of Chagas Disease Vectors in the Americas, Vol. III, Fiocruz, Rio de Janeiro, p. 747-792.

Carcavallo RU, Galíndez-Girón I, Catalá S, Jurberg J, Lent H, Galvão C, Barata JMS, Valderrama A 1998a. Some anatomic structures studied with scanning electron microscopy (SEM). In RU Carcavallo, I Galíndez-Girón, J Jurberg, H Lent (eds.), Atlas of Chagas Disease Vectors in the Americas, Vol. I, Fiocruz, Rio de Janeiro, p. 299-393.

Carcavallo RU, Galíndez-Gíron I, Jurberg J 1995. La región óculoocelar en el género Psammolestes Bergroth, 1911 (Hemiptera, Reduviidae, Triatominae). Entomol Vect 2: 113-116.
Carcavallo RU, Galíndez-Gíron I, Jurberg J, Martínez A 1994c. La región óculo-ocelar en el género Panstrongylus Berg, 1879 (Hemiptera, Reduviidae, Triatominae). Entomol Vect 1: 113-120.

Carcavallo RU, Galíndez-Gíron I, Martínez A, Jurberg J 1994a. Cuticular structures of Triatominae. Their taxonomic significance. Entomol Vect 1: 79-91.

Carcavallo RU, Jurberg J, Martínez A, Galíndez-Gíron I 1994b. La región óculo-ocelar en género Rhodnius Stål, 1859 (Hemiptera, Reduviidae, Triatominae). Entomol Vect 1:21-32.

Carcavallo RU, Jurberg J, Rocha DS, Galvão C, Noireau, Lent $\mathrm{H}$ 2002. Triatoma vandae n. sp. do Complexo oliveirai encontrada no estado de Mato Grosso, Brasil (Hemiptera: Reduviidae: Triatominae). Mem Inst Oswaldo Cruz 97: 649-654.

Carcavallo RU, Rodríguez MEF, Salvatella R, Susana I Curto de Casas, Sherlock IS, Galvão C, Rocha DS, Galíndez-Girón I, Otero MA, Arocha O, Martinez A, Da Rosa JÁ, Canale DM, Farr TH, Barata JMS 1998b. Habitats and related fauna. In RU Carcavallo, I Galíndez-Girón, J Jurberg, H Lent (eds.), Atlas of Chagas Disease Vectors in the Americas, Vol. II, Fiocruz, Rio de Janeiro, p. 561-600.

Espínola HN 1966. Nota sobre diferenças sexuais em formas imaturas de Triatominae (Hemiptera: Reduviidae). Rev Brasil Biol 26: 263-267.

Forero D, Weirauch C, Baena M. 2004. Synonymy of the reduviid (Hemiptera:Heteroptera) genus Torrealbaia (Triatominae) with Amphibolus (Harpactorinae), with notes on Amphibolus venator (Klug, 1830). Zootaxa 670: 1-12.

Galliard H 1935. Recherches sur les réduvidés hématophages Rhodnius et Triatoma. V. Morphologie de l'oeuf des triatomes. Ann Parasit Hum Comp 13: 511-527.

Galíndez-Girón I, Rocha DS, Lent H, Carcavallo RU, Jurberg J, Galvão C, Santos HB, Martínez A, Barata JMS, Rosa JA da 1998. Nynphal stages. In RU Carcavallo, I Galíndez-Girón, J Jurberg, H Lent (eds.), Atlas of Chagas Disease Vectors in the Americas, Vol. II, Fiocruz, Rio de Janeiro, p. 449-513.

Galvão C 2003. A sistemática dos triatomíneos (Hemiptera, Reduviidae), de De Geer ao DNA. Entomol Vect 10: 511-530.

Galvão C, Carcavallo RU, Rocha DS, Jurberg J 2003. A checklist of the current valid species of the subfamily Triatominae Jeannel, 1919 (Hemiptera, Reduviidae) and their geographical distribution, with nomenclatural and taxonomic notes. Zootaxa 202: 1-36.

Galvão C, Mc Aloon M, Rocha DS, Schaeifer CW, Patterson JS, Jurberg J 2005 Description of eggs and nymphs of Linshcosteus karupus Galvão, Patterson, Rocha \& Jurberg, 2002 (Hemiptera:Reduviidae:Triatominae). Ann Ent Soc Am 98 (in press)

Galvão C, Rocha DS, Jurberg J, Carcavallo RU 2001. Ampliação da distribuição geográfica de Triatoma deaneorum Galvão, Souza \& Lima, 1967, nova denominação para Triatoma deanei (Hemiptera, Reduviidae). Rev Soc Bras Med Trop 34: 587-589.

Hypša V, Tietz DF, Zrzavý J, Rego ROM, Galvão C, Jurberg J 2002. Phylogeny and biogeography of Triatominae (Hemiptera: Reduviidae): molecular evidence of a New World origin of the Asiatic clade. Mol Phyl Evol 23: 447-457.

Jurberg J, Vogel M 1994. Morfologia de huevos y ninfas de Triatoma matogrossensis Leite \& Barbosa, 1953 (Hemiptera: Reduviidae). Entomol Vect 1: 167-177. 
Jurberg J, Silva MBA, Galvão C, Rocha DS, Barbosa HS, Carcavallo RU 2002. Descrição dos ovos e ninfas de Triatoma jurbergi Carcavallo, Galvão \& Lent, 1998 vistos através de microscopia óptica e eletrônica de varredura (Hemiptera, Reduviidae). Mem Inst Oswaldo Cruz 97: 209-216.

Lent H, Wygodzisnky P 1979. Revision of the Triatominae (Hemiptera - Reduviidae) and their significance as vectors of Chagas' disease. Bull Amer Mus Nat Hist 163: 123-520.

Noireau F, Santos SM, Gumiel M, Dujardin JP, Soares MS, Carcavallo RU, Galvão C, Jurberg J 2002. Phylogenetic relationships within the oliveirai complex (Hemiptera, Reduviidae, Triatominae). Infec Gen Evol 2:11-17.

Paula AS, Dioatiuti L, Schofield CJ 2005. Testing the sistergroup relationship of the Rhodniini and Triatomini (Insecta: Hemiptera, Reduviidae, Triatominae). Molecular Phy-logenetics Evol 35: 712-718.

Pinto C 1924. Biologia do Triatoma brasiliensis Neiva. Sci Méd 2: 541-543.

Rosa JA da, Barata JMS, Barelli N 1992a. Spiracles of 5th instar nymphs in six species of Triatominae (Hemiptera, Reduviidae) using scanning electron microscopy. Mem Inst Oswaldo Cruz 87: 301-302.

Rosa JA da, Barata JMS, Barelli N, Santos JLF, Neto FMB 1992b. Sexual distincion between 5 th instar nymphs of six species of Triatominae (Hemiptera, Reduviidae). Mem Inst Oswaldo Cruz 87: 257-264.

Schaefer CW 2003. Triatominae (Hemiptera: Reduviidae): systematic questions and some others. Neotrop Entomol 32: $1-10$.

Silva MBA, Barbosa HS, Carcavallo RU, Galvão C, Jurberg J 1999. Placas apicais do lábio das ninfas de $1^{\circ}$ estádio de Triatoma guazu Lent \& Wygodzinsky, 1979 e Triatoma jurbergi Carcavallo, Galvão \& Lent, 1998 (Hemiptera, Reduviidae), vetores da doença de chagas. Entomol Vect 6: 663-668.

Silva MBA, Barbosa HS, Galvão C, Jurberg J, Carcavallo RU 2003. Comparative study of the stridulatorium sulcus, buccula and rostrum of the nymphs of Triatoma guazu Lent \& Wygodzinsky, 1979 and Triatoma jurbergi Carcavallo, Galvão \& Lent, 1998 by scanning electron microscopy (Hemiptera, Reduviidae). Mem Inst Oswaldo Cruz 98: 335-344.

Silva MBA, Jurberg J, Galvão C, Carcavallo RU 2000. Descrição dos ovos e ninfas de Triatoma guazu Lent \& Wygodzinsky, 1979 (Hemiptera, Reduviidae, Triatominae) vistos através de microscopia óptica e eletrônica de varredura. Entomol Vect 7: 311- 334

Silva MBA, Barbosa HS, Jurberg J, Galvão C, Carcavallo RU 2002. Comparative ultrastructural analysis of the antennae of Triatoma guazu and Triatoma jurbergi during the nymphal stage development (Hemiptera, Reduviidae). J Med Entomol 39: 705-715. 